\title{
THE USE OF E-PASSPORTS FOR INBOUND AIRPORT BORDER SECURITY SCREENING: THE PASSENGER PERSPECTIVE
}

\author{
David K. KNEALE, Glenn S. BAXTER, Graham WILD \\ School of Aerospace, Mechanical and Manufacturing Engineering, RMIT University, \\ Melbourne, Australia \\ E-mail: graham.wild@rmit.edu.au (corresponding author)
}

Received 10 December 2013; accepted 10 October 2014

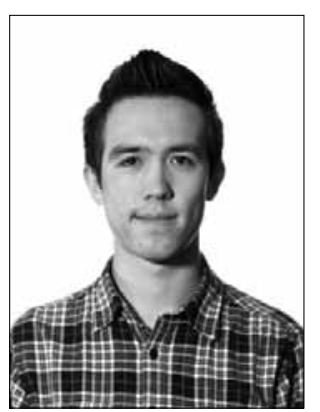

David K. KNEALE, B App $S c$

Education: Bachelor of Applied Science (Aviation), RMIT University, School of Aerospace, Mechanical and Manufacturing Engineering 2013.

Affiliations and functions: 2014 to present - Alumna of RMIT University.

Research interest: aviation and e-technologies.

Publications: author of 1 scientific article.

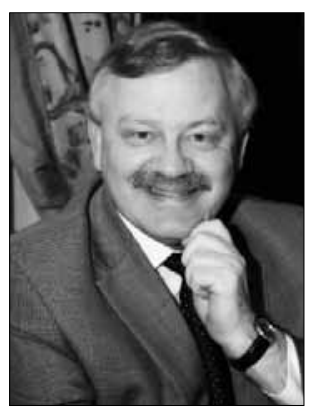

\section{Glenn S. BAXTER, $P h D$}

Education: bachelor of aviation studies, University of Western Sydney, Australia, 2000. Master of aviation studies, University of Western Sydney, Australia, 2002. PhD, School of Aviation, Griffith University, Brisbane, Australia, 2010.

Affiliations and functions: lecturer in Aviation Management and Deputy Director of Undergraduate Aviation Programs, RMIT University, School of Aerospace, Mechanical and Manufacturing Engineering.

Research interest: air cargo handling and operations; airport operations; sustainable aviation; supply chain management.

Publications: author of 2 scientific articles.

Present position: 2014 - present, Deputy Aviation Program Manager, RMIT University, School of Aerospace Mechanical and Manufacturing Engineering.

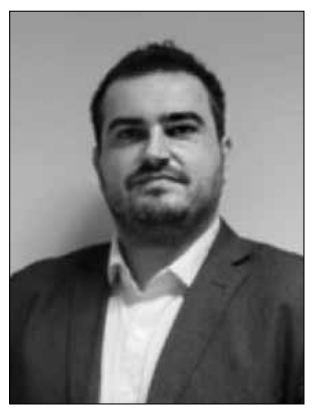

Graham WILD, PhD Eng

Date of birth: 1981.

Education: 2001-2004 - bachelor of science (Physics and Mathematics), Edith Cowan

University. 2004-2005 - bachelor of science honours (Physics), Edith Cowan University. 2008 Graduate Certificate (Research Commercialisation), Queensland University of Technology. 2006-2008 - master of science and technology (Photonics and Optoelectronics), the University of New South Wales. 2006-2010 - PhD (Engineering), Edith Cowan University. Affiliations and functions: 2010, postdoctoral research associate, Photonics Research Laboratory, Edith Cowan University. 2011-2012, lecturer of aviation systems, Edith Cowan University. 2012 - present, senior lecturer in Aerospace and Aviation, RMIT University, School of Aerospace Mechanical and Manufacturing Engineering. Research interest: aircraft systems; aerospace vehicle health monitoring; optical fibres; sensing and instrumentation; sustainable aviation; aviation technology. Publications: author of 10 articles, 4 book chapters, $60+$ conference presentations. Present position: 2014 - present, aviation program manager, RMIT University, School of Aerospace Mechanical and Manufacturing Engineering. 


\begin{abstract}
The aim of this study was to assess the use of machine readable passport systems for inbound airport border security screening, from the perspective of the travelling public. Traditional stamped passports are increasingly being replaced by electronic documents, or e-passports, and associated screening technology. This reality has been examined from the users' point-of-view. To investigate the use of e-passports, a survey was conducted on inbound international passengers arriving at Melbourne's Tullamarine Airport. Use in terms of usage rate, usability, ease of use, time, and satisfaction were investigated. In terms of gender, there was no difference in the five categories. For age, there was a statistical significant difference in terms of usage rate and clearance times, between younger (16 to 44 year olds) and older $(45+)$ passengers. That is, 16 to 44 year olds were more likely to use the technology, and as a result, took less time to clear customs. The direct relationship between these is apparent, the fact that more $45+$ passengers did not use the system resulted in their longer clearance times. More interesting is the fact that those $45+$ passengers that utilised the system reported it was as easy to use as 16 to 44 year olds, and were equally satisfied when using the system.
\end{abstract}

Keywords: biometrics, boarder security, e-passports, machine readable passport, machine readable travel document.

\section{Introduction}

\subsection{Aim}

In the past decade the use of biometrics and e-passports at airport border security screening has become widespread throughout the airport industry. The use of this technology is relatively new to airports around the world and is still in its infancy and any changes in the aviation industry can affect many of its activities and outcomes (Graham 2008). The implementation of the technology is considered essential given the increase in passenger demand, and the constraints associated with traditional processes (Költzsch 2006). The aim of this research was to investigate how the use of biometrics and e-passports at inbound airport border security screening affects passenger satisfaction and perceptions, using the SmartGate at Melbourne Airport as a case study. The research answers the following research question: what are the current passenger perceptions of SmartGate at Melbourne Airport in terms of SmartGate's usage, reliability, clearance times, ease of use, and overall satisfaction?

\subsection{Background}

Before the 21st century, airport security procedures traditionally placed a greater focus on passenger baggage rather than the individuals themselves. Identity fraud and extreme acts of terrorism such as the September 11 attacks have forced airports to focus on the individuals. In answer to this the airport industry and National Border Agencies have further developed this technology. This includes the use of biometric systems and e-passports both at inbound and outbound security checkpoints (Gkritza et al. 2006; Graham 2008: 132). Biometrics covers technologies in which unique identifiable attributes of a person are used for identification and authentication. These can include biological features such as fingerprints, iris prints, and facial features, all of which are used to verify/validate a person's identity when the individual is seeking to access computers, airports, databases, etc., (Biometrics Institute 2013). The International Civil Aviation Organization's (International... 2008b) Document 9303 describes a biometric system as an automated system capable of five functions:

1. Capturing a biometric sample from the holder of a machine readable travel document (MRTD) (i.e. an e-passport).

2. Extracting biometric data from the sample.

3. Comparing the specific biometric data with that contained in one of more references.

4. Deciding how well the two sources of data match.

5. Indicating whether identification or verification of identity has been achieved or not.

The use of biometrics and associated systems has been rolled out by ICAO member states according to guidelines set by ICAO and Annex 9 of the Chicago Convention on International Civil Aviation (i.e. facilitation). Chapter 3 of Annex 9 has set a deadline date on 24 November, 2015 for the expiration of all non-machine readable documents in an effort to implement a globally interoperable biometric system. The emergence of e-passports is a result of this goal. ICAO regards facial recognition as the most efficient type of biological feature to process and recommends that this be the norm across the industry. Member states have the option of using other features such as fingerprints in addition to facial features (International... 2005; International... 2008a: II-3; Siciliano 2007). Document 9303 further defines an e-passport as (International... 2008a):

A machine readable passport (MRP) containing a contactless integrated circuit chip within which data from the MRP data page is stored, a biometric measure of the passport holder, and a security object to protect the data with PKI cryptographic technology, which conforms to the specifications of Doc 9303, Part 1.

The public key infrastructure (PKI) certificate acts as a key to personal data held in e-passports and a public key directory (PKD) which enables interoperability across airports.

Industry professionals and authorities have suggested that the use of these MRPs and associated systems brings advantages including greater levels of security, increased throughput and capacity, abilities to cope with 
increasing traffic and reduction in waiting times (Crego, Bataller 2012; Department... 2013). As such, Australia designed its e-passport according to ICAO specifications, and it has been available to the general public since 2005 (Department... 2013). To cope with increasing travel demands, airport congestion and an anticipated increased use of e-passports and other MRTDs, the Australia Government's Custom and Border Security Protection Service trialled automated biometrics systems from 2002 to 2005. It named its biometrics system SmartGate and the latest version was introduced in 2007 to major airports around Australia and New Zealand (Australian... 2012).

\section{Literature review}

\subsection{Benefits and issues of using biometric systems and e-passports}

Experts and authorities such as M. Crego and C. Battaller (2012), K. Boussadia (2009), the Department of Foreign Affairs and Trade (n.d.) and the Australian Customs and Border Protection Service (Australian... 2012) have claimed that the use of biometric systems in conjunction with e-passports achieves specific advantages. These include the provision of greater protection against fraudulent passport misuse and tampering, reducing the risk of identity fraud (which costs countries billions of dollars each year), enhancing protection of borders through rapid, efficient and secure verification of incoming passengers and the ability to increase focus on high risk passengers. Further advantages are the reduction of facility costs and the need to hire additional government personnel, increased airport throughput and capacity, reductions in waiting times, enabling immigration officers to handle greater volumes of passengers and the option of self-service facilities.

M. Siciliano (2007) further observes that airports experiencing more rapid, secure and efficient processing of passengers are able to use space better and reduce the need to build or improve ever more expensive facilities. This is due to the direct correlation between the ability to move large crowds through port facilities and the size of the facility needed to handle crowds. In addition, this advantage will be a prime consideration when dealing with the anticipated sustained growth of air traffic in the future.

The use of e-passports allows customs, immigration and other authorities at the place of destination to use Advanced Passenger Information Systems (API) to electronically receive a list of passengers from air operators. This allows officials to process the information received well in advance of the arrival of a flight enabling further actions to be taken if necessary (Siciliano 2007).
In contrast, there are over 104 countries currently distributing e-passports. Some of these countries are producing e-passports that are not compliant with ICAO specifications. These differing passports and the use of different biometric system configurations such as multimodal systems (i.e. the use of more than one biometric identifier, e.g. face and iris recognition) or systems produced by different manufacturers create issues with interoperability across airports. The incompatibility of passports and different biometric systems are not in line with ICAO's goal of harmonization across the industry (International... 2012; Siciliano 2012).

In addition, reports at Manchester, Bristol, Cardiff and Heathrow airports have highlighted several weaknesses found from observations of their biometric systems/gates and passenger surveys. These included the inability of families to use the system (minimum age of 18 to obtain an e-passport), effective use of gates relies on staff assistance (sometimes not possible due to resource restrictions), gates going out of order/offline for several minutes, gate malfunctions (locking passengers within gates) and high rejection rates for passengers from specific countries (possibly using different types of e-passports). Other situations included a passenger going through with her husband's passport, high system sensitivity creating high rejection rates, low system sensitivity creating incorrect matches and, finally, manual procedures processing more than double or triple the amount of passengers than 2 or 3 operational gates (Vine 2010, 2011, 2012).

Furthermore, gates that go out of order and need maintenance require a contractor that is able to fix the gates within an appropriate time-frame. Without this ability the biometric system efficiency is sacrificed (Vine 2010).

S. K. Modi (2011) outlines other weaknesses such as the inability of systems to match people to database information when different real-time poses and expressions are scanned. Physiological factors are another problem. This includes occlusion due to artefacts such as sunglasses and hats. Short-term aging does not have a significant effect on face recognition but long-term aging has yet to be studied and could be an issue for those holding e-passports nearing their 10 year expiry date. Insufficient lighting is also a barrier to systems due to reflectance properties of the skin. This and objects in the background of real-time images may affect performance. S. K. Modi further indicates that distance and motion are a weakness if passengers are too far away from the camera or do not stand still (Modi 2011).

\subsection{Operational performance and customer satisfaction criteria}

Airports Council International has recommended a number of measurable performance criteria 
concerning biometric systems, e-passports and airport operations (Airports... 2005). These include interoperability, speed, security, reliability, scalability and ICAO and ISO (International Organization for Standardization) Certification analysed changes in satisfaction concerning airport security screening shortly after the September 11 attacks (Gkritza et al. 2006). Their results indicated that customer satisfaction is influenced by waiting time, but it is not the most important criteria. A. Graham (2005) offers a broad criterion list of overall performance and satisfaction at airports. This in relation to biometric systems includes aircraft delays, waiting times and queue lengths. The Australian Competition and Consumer Commission (ACCC) further includes space/ area available, number of immigration desks, signage/way-finding and walking distances as criteria (Australian... 2007, 2013). D. Fodness and B. Murray (2007) focus on staff availability and competence, public announcement systems, lighting and adequate space to prevent crowding. A. Correira et al. (2008) indicate that the ACI criteria also include waiting times, processing times, walking time, walking distance, level changes, orientation/information and space availability for passengers. They further suggest that staff's overall attitude, appearance; ease of locating, competence/responsiveness, friendliness and availability/reliability is of importance. S. Gold (2012) indicates that airports should also take into account the amount of physical space a system requires. Finally, N. Ashford et al. (2011) define processing rates as the number of entities (e.g. passengers) processed by a single resource in a given unit of time (e.g. minutes and seconds). They regard 0 to 7 minutes as short to acceptable clearance time for passport control (arrival) and 7 to 15 minutes as acceptable to long.

T. L. Mitzner et al. (2010) indicate that other studies have found the stereotype of older adults being unable, unwilling, and afraid to use technology to be generally true in some cases. However, T. L. Mitzner et al. (2010) found that older adults actually have a more complex knowledge, perception and use of technology than some may give them credit for. Once they have adopted and familiarized themselves with a type of technology they have a stronger perception of its benefits and usefulness. L. T. Mitzner et al. (2010) suggest that greater emphasis should be put into the education of older adults concerning the use and benefits of new technology.

\subsection{SmartGate trials in Australia}

As mentioned previously, Australia's own biometric system named SmartGate was trialled between 2003 and 2005. In 2004, the Australian Customs Service (2004b) claimed that SmartGate takes 17 seconds to process a passenger while manual procedures took 48 seconds on average. ACNielsen (2005) conducted a survey in which the participants included Qantas crew and passengers. In general, enrolment to use SmartGate increased with participant age which indicated that older passengers were more willing to use SmartGate. Over a period of several months it was reported that $85 \%$ of Qantas crew always used SmartGate while 75\% of passengers always used it. Reliability was a concern for those that did not always use SmartGate because it was either not working or they had previous difficulties with the system. $90 \%$ of crew who used SmartGate some of the time rated it as easy to use while $5 \%$ rated it as neither easy nor difficult and $5 \%$ rated it as difficult. $89 \%$ of passengers who used SmartGate some of the time rated it as easy to use while $8 \%$ rated it as neither easy nor difficult and $4 \%$ rated it as difficult. $98 \%$ of crew preferred SmartGate over manual procedures and $88 \%$ preferred SmartGate over other systems in other countries. $99 \%$ of passengers preferred SmartGate over manual procedures while $93 \%$ of them preferred SmartGate over systems in other countries. $5 \%$ of crew and $3 \%$ of passengers were concerned for their privacy in regard to using SmartGate. ACNielsen concluded that the results and findings from their survey provided feedback that was positive and indicated that SmartGate was an effective system for both user groups.

The Defence Science and Technology Organisation (DSTO) completed a technical assessment of SmartGate. Their results showed that the percentage of users incorrectly rejected as being themselves by the system (i.e. A being falsely rejected as being $\mathrm{A}$ ) was $2 \%$ and the percentage of falsely identified users (i.e. B being falsely accepted as A) was less than $1 \%$ for each presentation of the passport (Australian... 2004a).

After the trial, ACTSAFE Australia recommended a rearrangement of queuing barriers and clearer user instructions (Australian... 2004a).

These surveys and trials, however, do not apply to the current SmartGate system as it has been upgraded since that time and uses different configurations (Australian... 2012).

\section{Methodology}

An empirical and exploratory single-site case study (Yin 2009) was performed utilising inbound international passengers that had arrived through Melbourne's Tullamarine Airport. Data was collected by surveying passengers about their use of SmartGate. The survey data was then analysed to quantify the passengers' perception of SmartGate. 


\subsection{Survey design}

SmartGate is only applicable to inbound international flights therefore the first question of the survey asked if the respondent had recently returned through Tullamarine Airport, as an international passenger through customs. Since only international passengers who are Australian or New Zealand citizens can currently utilise SmartGate, the next question asked the respondents for their nationality. Next, the respondents were inquired about their age, specifically if they were over the age of 16 , as this is the minimum age to use an e-passport and the SmartGate system. Another piece of demographic information collected was gender.

The survey was structured around the major criteria found in the literature review's operational performance and passenger satisfaction criteria. SmartGate's trial surveys were also taken into account when setting questions as these were specifically applicable to the objectives of this research. Questions were based on SmartGate's usage (used or did not use), reliability (whether SmartGate worked or did not work), ease of use (easy, neither easy nor difficult, or difficult), clearance time, and SmartGate's overall satisfaction rating.

\subsection{Hypotheses}

The following null hypotheses were formed with the influence from the literature and SmartGate trial surveys:

1. Passengers aged $45+$ are just as likely to use SmartGate as passengers aged 16 to 44 .

2. Passengers aged $45+$ are as successful when using SmartGate as passengers aged 16 to 44 .

3. Passengers aged 45+ find SmartGate equally easy to use as passengers aged 16 to 44 .

4. Passengers aged $45+$ take the same length of time to clear passport control as passengers aged 16 to 44 .

5. Passengers aged $45+$ are as satisfied when using SmartGate as passengers aged 16 to 44 .

\subsection{Data analysis}

The data was analysed using Microsoft Excel. Specifically, a t-test with two samples assuming unequal variances was utilised. The standard significance level $(\alpha)$ of 0.05 (that is, $95 \%$ confidence) was used to determine whether the results were statistically significant.

\section{Results and analysis}

Table 1 presents the overall survey results. The total number of respondents that were inbound international passengers arriving through customs at Melbourne's Tullamarine Airport, who were also either Australian or New Zealand e-passport holders, and over the age of 16, was 130.
Table 1. Statistical summary of responses

\begin{tabular}{|c|c|c|}
\hline & Respondents & Percentage (\%) \\
\hline \multicolumn{3}{|l|}{ Gender } \\
\hline Male & 70 & 53.8 \\
\hline Female & 60 & 46.2 \\
\hline \multicolumn{3}{|l|}{ Age } \\
\hline $16-24$ & 15 & 11.5 \\
\hline $25-34$ & 42 & 32.3 \\
\hline $35-44$ & 30 & 23.1 \\
\hline $45-54$ & 19 & 14.6 \\
\hline $55-64$ & 15 & 11.5 \\
\hline $65-74$ & 8 & 6.2 \\
\hline 75 and over & 1 & 0.8 \\
\hline \multicolumn{3}{|l|}{ Reliability } \\
\hline Worked & 66 & 50.8 \\
\hline Eventually worked & 16 & 12.3 \\
\hline Didn't work & 12 & 9.2 \\
\hline Didn't use it & 36 & 27.7 \\
\hline \multicolumn{3}{|l|}{ Ease of use } \\
\hline Easy & 50 & 38.5 \\
\hline Neither easy nor difficult & 37 & 28.5 \\
\hline Difficult & 7 & 5.4 \\
\hline Not applicable & 36 & 27.7 \\
\hline \multicolumn{3}{|l|}{ Clearance time } \\
\hline Less than 5 mins & 24 & 18.5 \\
\hline $5-10$ mins & 54 & 41.5 \\
\hline $10-15$ mins & 29 & 22.3 \\
\hline $15-20$ mins & 11 & 8.5 \\
\hline $20-25$ mins & 6 & 4.6 \\
\hline More than 25 mins & 6 & 4.6 \\
\hline \multicolumn{3}{|l|}{ Overall Rating } \\
\hline Very unsatisfied & 4 & 3.1 \\
\hline Unsatisfied & 8 & 6.2 \\
\hline Neutral & 7 & 5.4 \\
\hline Satisfied & 39 & 30 \\
\hline Very Satisfied & 36 & 27.7 \\
\hline Not applicable & 36 & 27.7 \\
\hline
\end{tabular}

\subsection{Usage}

First the likelihood of usage of (to use or not use) SmartGate by specific demographic groups was investigated. Based on the sample considered here, males and females were equally likely to utilise SmartGate.

To test, the "did not use SmartGate" option of the $1^{\text {st }}$ hypothesis, was assigned a value of " 1 ", and the "used SmartGate" option was assigned a value of " 2 ". Figure 1 shows that $81.6 \%$ of passengers aged 16 to 44 used SmartGate. In contrast, only $53.5 \%$ of passengers aged $45+$ used SmartGate.

Table 2 shows the results of the t-test for the usage rates. Table 2 indicates that the two-tailed test has a confidence level of $99.8 \%$. This value is greater than the $95 \%$ confidence level to be considered statistically significant, and as such we can reject the null hypothesis. Table 2 also shows that the mean for the passengers aged $45+$ is greater than the mean for passengers aged 16 to 44 . This clearly indicates that passengers aged $45+$ were less likely to use SmartGate relative to passengers aged 16 to 44 . 


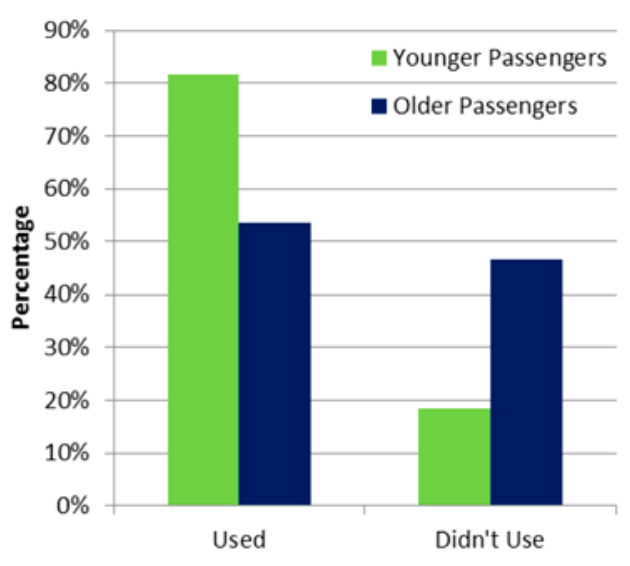

Fig. 1. Usage by age

Table 2. Usage by age

\begin{tabular}{|l|c|c|}
\hline & Age $\leq 44$ & Age $\geq 45$ \\
\hline Mean & 1.816091954 & 1.534883721 \\
\hline Variance & 0.151831061 & 0.254706534 \\
\hline Observations & 87 & 43 \\
\hline $\begin{array}{l}\text { Hypothesized Mean } \\
\text { Difference }\end{array}$ & 0 & \\
\hline df & 68 & \\
\hline $\mathrm{t}$ Stat & 3.211221072 & \\
\hline $\mathrm{P}(\mathrm{T}<=\mathrm{t})$ two-tail & 0.002019664 & \\
\hline $\mathrm{t}$ Critical two-tail & 1.995468931 & \\
\hline
\end{tabular}

\subsection{Usability}

Following the usage rate of SmartGate amongst the demographics, the usability of SmartGate was investigated. The usability was measured in terms of SmartGates rate of clearance for those who utilised it. That is, whether or not the passengers' e-passport and biometrics were accepted or rejected. As with the usage rate, there was no statistical difference in terms of gender for the usability of SmartGate.

For hypothesis 2, the "worked" option was assigned a value of "1", and the "didn't work" option was assigned a value of "2". Figure 2 shows that SmartGate successfully cleared $87.3 \%$ of passengers aged 16 to 44 , and cleared $87 \%$ of passengers aged $45+$.

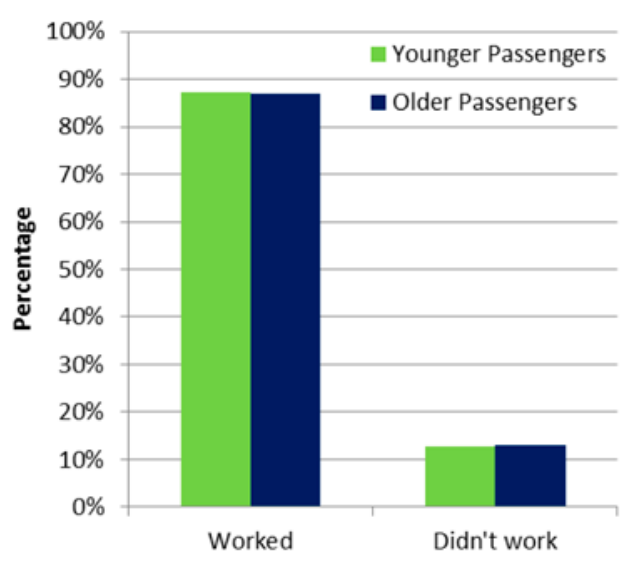

Fig. 2. Usability by age
Table 3 shows the results of the t-test for the usability. Table 3 indicates that the two-tailed test has a confidence level of $3.5 \%$. This value is less than the $95 \%$ confidence level considered statistically significant, and as such we must accept the null hypothesis. That is, whether SmartGate "worked" or "didn't work" was independent of the users' age. From this we can conclude that SmartGate was able to process all passengers' data equally.

Table 3. Usability by age

\begin{tabular}{|l|c|c|}
\hline & Age $\leq 44$ & Age $\geq 45$ \\
\hline Mean & 1.126760563 & 1.130434783 \\
\hline Variance & 0.112273642 & 0.118577075 \\
\hline Observations & 71 & 23 \\
\hline $\begin{array}{l}\text { Hypothesized Mean } \\
\text { Difference }\end{array}$ & 0 & \\
\hline $\mathrm{df}$ & 36 & \\
\hline $\mathrm{t}$ Stat & -0.044764818 & \\
\hline $\mathrm{P}(\mathrm{T}<=\mathrm{t})$ two-tail & 0.964542159 & \\
\hline $\mathrm{t}$ Critical two-tail & 2.028094001 & \\
\hline
\end{tabular}

\subsection{Ease of use}

The next question investigated SmartGates ease of use amongst the demographics for those passengers that used the system. Ease of use was measured on a three point scale, of "easy to use", "neither easy nor difficult", or "difficult". As with the previous questions, there was no difference in the perceived ease of use between the genders.

In investigating this hypothesis (3), relative to the passengers operation of SmartGate, the "easy to use", option was assigned a value of "1", the option "neither easy nor difficult" was assigned a value of " 2 ", and the "difficult" option was assigned a value of " 3 ". Figure 3 shows that $53.5 \%$ of passengers aged 16 to 44 (who used SmartGate) thought that it was "easy to use", while 8.5\% thought it was "difficult" to use. For passengers aged $45+$ (who used SmartGate), $52.2 \%$ of them thought it was "easy to use", while $4.3 \%$ thought it was "difficult" to use.

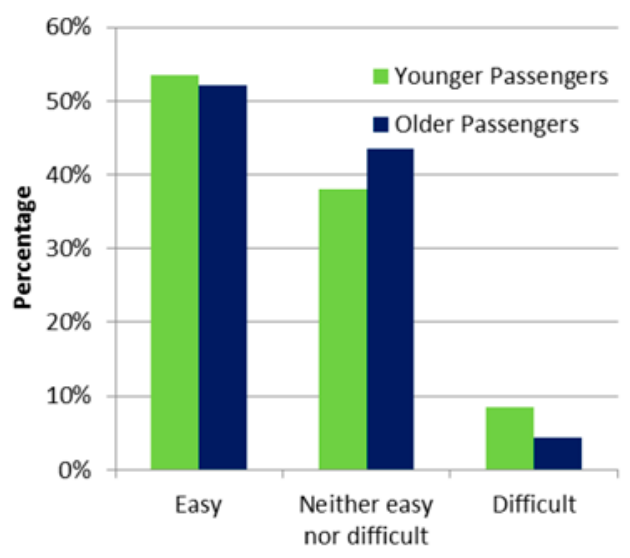

Fig. 3. Ease of use by age 
Table 4 shows the results of the t-test for the ease of use. Table 4 indicates that the two-tailed test has a confidence level of $15 \%$. This value is less than the $95 \%$ confidence level considered statistically significant, and as such we must accept the null hypothesis. That is, how easy passengers perceived SmartGate to use was independent of the users' age.

Table 4. Ease of use by age

\begin{tabular}{|l|c|c|}
\hline & Age $\leq 44$ & Age $\geq 45$ \\
\hline Mean & 1.549295775 & 1.52173913 \\
\hline Variance & 0.422535211 & 0.351778656 \\
\hline Observations & 71 & 23 \\
\hline $\begin{array}{l}\text { Hypothesized Mean } \\
\text { Difference }\end{array}$ & 0 & \\
\hline $\mathrm{df}$ & 41 & \\
\hline $\mathrm{t}$ Stat & 0.189055151 & \\
\hline $\mathrm{P}(\mathrm{T}<=\mathrm{t})$ two-tail & 0.850982364 & \\
\hline $\mathrm{t}$ Critical two-tail & 2.01954097 & \\
\hline
\end{tabular}

\subsection{Clearance times}

The time to clear customs was compared between the two age groups for all passengers (those that used SmartGate and those that did not) for the demographics. Once again, there was no statistical difference between the clearance times of male and female passengers.

Hypothesis 4 utilised a six point scale, based on 5 minute increments. That is, 0 to 5 minutes, 5 to 10 minutes, 10 to 15 minutes, 15 to 20 minutes, 20 to 25 minutes, and $25+$ minutes. These were assigned values from " 1 " to " 6 " respectively. Figure 4 shows the distribution of times for passengers for both age groups.

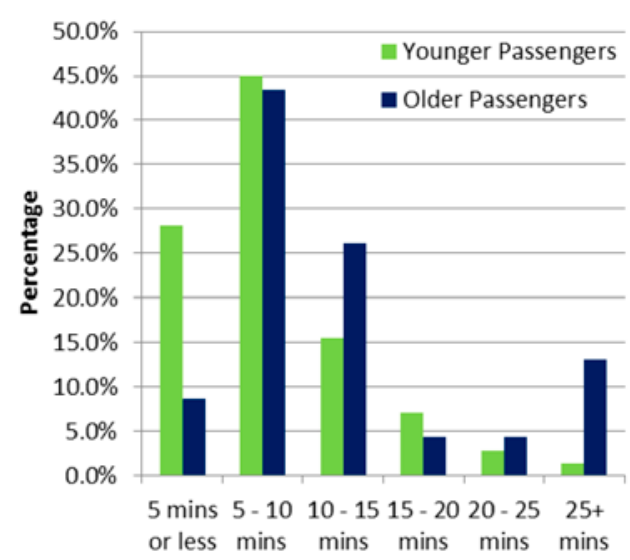

Fig. 4. Clearance times by age

Table 5 shows the results of the t-test for the customs clearance times. Table 5 indicates that the two-tailed test has a confidence level of $96.7 \%$. This value is greater than the $95 \%$ confidence level to be considered statistically significant, and as such we can reject the null hypothesis.
Table 5 also shows that the mean for the passengers aged $45+\left(\mu_{2}=2.91\right)$ is greater than the mean for passengers aged 16 to $44\left(\mu_{1}=2.15\right)$. This clearly indicates that passengers aged $45+$ took longer to clear customs relative to passengers aged 16 to 44 .

Table 5 . Clearance times by age

\begin{tabular}{|l|c|c|}
\hline & Age $\leq 44$ & Age $\geq 45$ \\
\hline Mean & 2.154929577 & 2.913043478 \\
\hline Variance & 1.189939638 & 2.264822134 \\
\hline Observations & 71 & 23 \\
\hline $\begin{array}{l}\text { Hypothesized Mean } \\
\text { Difference }\end{array}$ & 0 & \\
\hline df & 30 & \\
\hline $\mathrm{t}$ Stat & -2.233321389 & \\
\hline $\mathrm{P}(\mathrm{T}<=\mathrm{t})$ two-tail & 0.033136118 & \\
\hline $\mathrm{t}$ Critical two-tail & 2.042272456 & \\
\hline
\end{tabular}

\subsection{Overall rating}

The final question concerned the overall rating given by passengers that used SmartGate amongst the demographics. As with all the other questions, gender showed no significant statistical difference for the overall satisfaction rating given when using SmartGate.

For hypothesis 5, a typical five point scale was used to measure satisfaction. The options were "strongly dissatisfied", "dissatisfied", "neutral”, "satisfied", and "strongly satisfied". These options were then assigned values from " 1 " to " 5 " respectively. Figure 5 shows the distribution of overall ratings for passengers for both age groups.

Table 6 shows the results of the t-test for the overall satisfaction. Table 6 indicates that the two-tailed test has a confidence level of 3.6\%. This value is less than the $95 \%$ confidence level considered statistically significant, and as such we must accept the null hypothesis. That is, the overall satisfaction of passengers that used SmartGate was independent of the users' age.



Fig. 5. Rating by age 
Table 6. Rating by age

\begin{tabular}{|l|l|l|}
\hline & \multicolumn{1}{|c|}{ Age $\leq 44$} & \multicolumn{1}{c|}{ Age $\geq 45$} \\
\hline Mean & 4.014084507 & 4 \\
\hline Variance & 1.014084507 & 1.818181818 \\
\hline Observations & 71 & 23 \\
\hline $\begin{array}{l}\text { Hypothesized Mean } \\
\text { Difference }\end{array}$ & 0 & \\
\hline $\mathrm{df}$ & 30 & \\
\hline $\mathrm{t}$ Stat & 0.046102141 & \\
\hline $\mathrm{P}(\mathrm{T}<=\mathrm{t})$ two-tail & 0.963534366 & \\
\hline $\mathrm{t}$ Critical two-tail & 2.042272456 & \\
\hline
\end{tabular}

\section{Discussion}

T. L. Mitzner et al. (2010) stated that there are many stereotypes in relation to older people. These stereotypes perceive older adults as unable, unwilling and afraid to use technology. The results of this study found that passengers aged 16 to 44 and passengers aged $45+$ were similar in their satisfaction as well as similar in perceptions of SmartGate's ease of use. They both had high satisfaction and thought SmartGate was either easy to use or neither easy nor difficult. This could be a result of passengers having used SmartGate more than once and that they were already familiar with it. If so, this would be consistent with studies by T. L. Mitzner et al. (2010) stating that older people who have already adopted certain technology generally have a positive perception towards it and a greater ability to use this technology. Our results and analysis indicated that, in comparison to passengers aged 16 to 44 , there was a significant difference in the usage rate of SmartGate for passengers aged 45+ (i.e. they were less likely to use the technology) and as a result they took longer to clear immigration through SmartGate. The causes of these phenomena could include unfamiliarity with SmartGate, greater familiarity with manual procedures, unawareness of its existence or whether they were eligible to use it and simply an unwillingness to change. The ACCC (2007) note that airports and airlines could make a greater effort to educate and inform passengers of how to use SmartGate through mediums such as better signage, instructional pamphlets, announcements and videos throughout the airport or on aircraft. Implications for these actions could create greater awareness for the system, incentive to use it, higher usage, greater throughput, less congestion, a more secure environment, greater trust towards the system, higher satisfaction levels and reduced waiting times.

The success rate between age groups was very similar and almost equal. Over $80 \%$ of passengers were successfully cleared through customs. This means that SmartGate was just as able to match live data from younger passengers to information within its own database as it could with older passengers. However, long- term aging effects could be affecting performance and hence the lower success rate compared to the SmartGate trials (ACNielsen 2005). E-passports are relatively new and many have not come close to their 10 year expiry deadline. As S. K. Modi (2011) suggests, other reasons for failure such as lighting, distance and movement in real-time could be contributing factors in the results. A further study can be performed on SmartGate's success rate to investigate the effects of ageing facial features within a 10 year period. Once again, education and information concerning the operation of SmartGate could increase its success rate.

As M. Siciliano (2007) suggests, biometric systems and the e-passport can result in faster immigration clearance times. Our results agree with this statement as those who used SmartGate had much shorter clearance times than those who did not use it. Although our results are based on 5 minutes increments, most of those who used SmartGate reported that they cleared immigration within or around $\mathrm{N}$. Ashford et al. (2011) short to acceptable timeframe (i.e. 0-7 mins). However, airports and airlines need to increase SmartGate's usage rate in order to achieve the benefits that are intended when implementing e-passports and biometric systems. At the time of this paper, only Australian, New Zealand, U.S.A. and U.K. residents are able to use SmartGate. The preparations for introducing eligibility to other nationalities should enable airports to achieve these benefits on a greater scale and promote interoperability across the industry (International... 2012; Siciliano 2012).

\section{Conclusions}

The case study of passenger surveys on Melbourne Airport's SmartGate system found significant results that can aid airports, airlines, authorities and system designers to understand SmartGate's weaknesses from the passengers' point-of-view, and further study what improvements can be made. Results found from these surveys included several significant outcomes. Older passengers are not as likely to use SmartGate as younger passengers. SmartGate successfully cleared the majority of passengers and there was no difference between its acceptance of older and younger passengers. Older passengers and younger passengers had similar perceptions of SmartGate's ease of use with most of them thinking it was either easy or neither easy nor difficult to use. Clearance times were faster for those who used SmartGate but older passengers took longer to be cleared by the system than younger passengers. Both older passengers and younger passengers had similar satisfaction levels and over $70 \%$ of both groups were either satisfied or very satisfied.

There are several possible reasons why older passengers were less likely to use SmartGate. These include unfamiliarity with SmartGate, greater familiarity with 
manual procedures, unawareness of its existence or whether they were eligible to use it and an unwillingness to change. Some tactics that airports and airlines could use to address these could be to make greater efforts to educate and inform passengers of how to use SmartGate through mediums such as better signage, instructional pamphlets, announcements, and videos throughout the airport or on aircraft.

Possible implications for all solutions mentioned could include more incentives for SmartGate usage, higher usage and satisfaction, greater trust towards the system, greater throughput, less congestion, a more secure environment, higher revenue, reduced waiting times or shorter queues and ultimately a greater reputation for airports and system designers.

\section{References}

ACNielsen. 2005. SmartGate 2 study, January 2005. Final Report [online], [cited 9 December 2013]. Available from Internet: http://www.aph.gov.au/ /media/Estimates/Live/ legcon_ctte/estimates/bud_0506/ag/qon_229_acs_att1.ashx

Airports Council International. 2005. The Application of Biometrics at Airports [online], [cited 9 December 2013]. Available from Internet: http://www.aci.aero/aci/aci/file/ Free\%20docs/ACI\%20Biometric\%20Position\%20FINAL. pdf

Ashford, N.; Mumayiz, S. A.; Wright, P. H. 2011. Airport Engineering: Planning, Design, and Development of 21st Century Airports. $4^{\text {th }}$ ed. Hoboken, NJ: John Wiley \& Sons. http://dx.doi.org/10.1002/9780470950074

Australian Competition and Consumer Commission. 2007. Airport Quality of Service Monitoring: Discussion paper [online], [cited 2 December 2013]. Available from Internet: http://accc.gov.au/system/files/Airport\%20quality\%20 of $\% 20$ service $\% 20$ monitoring\%20discussion\%20paper.pdf

Australian Competition and Consumer Commission. 2013. Guideline for Quality of Service Monitoring at Airports [online], [cited 2 December 2013]. Available from Internet: http://www.accc.gov.au/system/files/Airport\%20 quality $\% 20$ of $\% 20$ service $\% 20$ monitoring\%20guideline $\% 20$ \%28June\%202013\%29.pdf

Australian Customs Service. 2004a. Overview of Smartgate Trial (current at February 2004) [online], [cited 1 December 2013]. Available from Internet: http://www.aph.gov.au/ / media/Estimates/Live/legcon_ctte/estimates/bud_0405/ ags/106-117.ashx

Australian Customs Service. 2004b. SmartGate [online], [cited 1 December 2013]. Available from Internet: http://www. docsrush.net/1262291/media-background-smartgate-information-sheet.html

Australian Customs and Border Protection Service. 2012. SmartGate [online], [cited 1 December 2013]. Available from Internet: http://www.customs.gov.au/smartgate/ smartgate.asp

Biometrics Institute. 2013. About Biometrics [online], [cited 3 December 2013]. Available from Internet: http://www.biometricsinstitute.org/pages/about-biometrics.html

Boussadia, K. 2009. The evolution of airport screening technology, Biometric Technology Today 17(2): 7-8. http://dx.doi.org/10.1016/S0969-4765(09)70056-6
Crego, M.; Bataller, C. 2012. Biometrics boost business outcomes and security in public services, Biometric Technology Today 3: 8-11. http://dx.doi.org/10.1016/S0969-4765(12)70073-5

Correira, A.; Wirasinghe, S. C.; de Barros, A. G. 2008. Overall level of service measures for airport passenger terminals, Transportation Research Part A: Policy and Practice 42(2): 330-346. http://dx.doi.org/10.1016/j.tra.2007.10.009

Department of Foreign Affairs and Trade. 2013. The Australian ePassport [online], [cited 2 December 2013]. Available from Internet: http://www.dfat.gov.au/dept/passports

Fodness, D.; Murray, B. 2007. Passengers' expectations of airport service quality, Journal of Services Marketing 21(7): 492-506. http://dx.doi.org/10.1108/08876040710824852

Gkritza, K.; Niemeier, D.; Mannering, F. 2006. Airport security screening and changing passenger satisfaction: an exploratory assessment, Journal of Air Transport Management 12(5): 213-219. http://dx.doi.org/10.1016/j.jairtraman.2006.03.001

Graham, A. 2005. Airport benchmarking: a review of the current situation, Benchmarking: An International Journal 12(2): 99-111.

Graham, A. 2008. Managing Airports: An International Perspective. $3^{\text {rd }}$ ed. Oxford, UK: Butterworth-Heinemann.

Gold, S. 2012. Border control biometrics and surveillance, Biometric Technology Today 7: 9-11.

International Civil Aviation Organization. 2005. Annex 9 to the Convention on International Civil Aviation [online], [cited 9 December 2013]. Available from Internet: http://www.ifrc. org/docs/IDRL/Chicago\%20Convention\%20Annex\%209.pdf

International Civil Aviation Organization. 2008a. Document 9303: Part 1, Volume 1 [online], [cited 9 December 2013]. Available from Internet: http://www.icao.int/publications/ Documents/9303_p1_v1_cons_en.pdf

International Civil Aviation Organization. 2008b. Document 9303: Part 3, Volume 2 [online], [cited 9 December 2013]. Available from Internet: http://www.icao.int/publications/ Documents/9303_p3_v2_cons_en.pdf

International Civil Aviation Organization. 2012. ePassport Implementation and the ICAO pkd [online], [cited 9 December 2013]. Available from Internet: http://www. icao.int/publications/journalsreports/2012/MRTD_Report_Vol7_No3.pdf

Költzsch, G. 2006. Biometric technologies in passenger clearance, Aviation 10(4): 18-24.

Mitzner, T. L., et al. 2010. Older adults talk technology: technology usage and attitudes, Computers in Human Behaviour 26(6): 1710-1721. http://dx.doi.org/10.1016/j.chb.2010.06.020

Modi, S. K. 2011. Biometrics in Identity Management: Concepts to Applications. $1^{\text {st }}$ ed. Boston: Artech House.

Siciliano, M. 2007. ePassports: examining the benefits, International Airport Review 1(4): 73-77.

Siciliano, M. 2012. ICAO Compliant Epassports: Improving Border Security and Ensuring Safer Air [online], [cited 4 December 2013]. Available from Internet: http://www. icao.int/publications/journalsreports/2012/MRTD_Report_Vol7_No3.pdf

Vine, J. 2010. An Inspection of Border Control at Manchester Airport [online], [cited 3 December 2013]. Available from Internet: http://icinspector.independent.gov.uk/wp-content/uploads/2010/03/An-inspection-of-border-controlat-Manchester-Airport.pdf 
Vine, J. 2011. Inspection of UK Border Agency Operations in Wales and the South West [online], [cited 3 December 2013]. Available from Internet: http://icinspector.independent.gov.uk/wp-content/uploads/2010/07/Inspectionof-UK-Border-Agency-operations-in-Wales-and-theSouth-West.pdf

Vine, J. 2012. Inspection of Border Control Operations at Terminal 3, Heathrow Airport [online], [cited 3 December 2013]. Available from Internet: http://icinspector. independent.gov.uk/wp-content/uploads/2012/05/Inspection-of-Border-Control-Operations-at-Terminal-3-Heathrow-Airport.pdf

Yin, R. K. 2009. Case Study Research: Designs and Methods. $4^{\text {th }}$ ed. Thousand Oaks, CA: Sage publications. 